\author{
Л.П. Дронова \\ Томский государственный университет, \\ (Россия, Томск) \\ lpdronova@mail.ru
}

\title{
ЕЩЕ РАЗ О ФОРМИРОВАНИИ ПОНЯТИЯ «ВРЕД» В СЛАВЯНСКИХ ЯЗЫКАХ
}

В статье привлекается внимание к сложности выявления мотивировочного признака ядерной лексемы лексико-семантического поля «Вред» в славянских языках.

Проведенное сопоставление мотивационно-генетических характеристик лексем, наиболее близких по семантике рус. вред и веред, сравнение семантических полей омонимичных этимологических гнезд *uer-d-, к которым Ю. Покорный относит слав. *verdb в разных значениях ('нарыв; болезнь' и 'рана'), отсутствие значений типа 'нарыв, чирей’ у греческих эквивалентов ст.-слав. врtдb, а также проверка фактов некоторых фактов древнегерманских языков на наличие/отсутствие генетической близости рефлексам слав. *verdb - все это вместе дает основание предположить, что первичным для слав. *verds было обозначение нарыва/раны, повреждения воспалительного характера, проявляющегося на коже и связанного с какой-либо болезнью (откуда и значение ‘болезнь' у производных *verd можно, эта номинация формировалась как различающая обозначение раны, повреждения, нанесенного острым предметом, оружием, выражаемого слав. *rana, предполагаемым однокорневым образованием от и.-е. *urōnā.

Ключевые слова: славянские языки, этимологическое гнездо слав. *verdz, славяно-германские связи.

Мы уже обращались к мотивационно-генетической характеристике ядра лексико-семантического поля «Вред» [Дронова, Лю 2016]. Актуальность изучения мотивационно-генетических характеристик всех лексических единиц поля и прежде всего его ядерной единицы не вызывает сомнения, поскольку мотивационные связи, существующие в языке, характеризуют структуру ментального мира носителей языка, а в данном случае его значимого фрагмента - отрицательной утилитарной оценки. Повторное обращение к этой теме вызвано тем, что «вредное оказалось вредным», и мы не смогли сделать однозначные выводы по мотивационно-генетической характеристике ядерной лексемы, проанализировав 
функционально-семантические особенности, мотивационные отношения в лексико-семантическом поле «Вред» на материале литературного русского языка, его диалектов, исторических фактов, привлекая семантику однокорневых дериватов других славянских языков. Анализ семантического поля производных праслав. *verdb выявил два семантических центра - с конкретной семантикой 'нарыв, чирей, язва' и общей 'повреждать, портить/повреждение, порча, ущерб', и не нашлось аргументов, позволяющих считать первичным мотивировочным признаком либо обозначение заболевания воспалительного характера, проявляющиеся на коже ('нарыв, язва, гнойник'), либо обозначение деструктивного воздействия (внутреннего, внешнего), прежде всего проявляющегося на коже как всякого рода гнойники.

Этимологические источники предлагают два варианта исторического развития мотивационных отношений. Первый вариант: по наиболее распространенному мнению авторов этимологических словарей, считающих старшим значение 'нарыв, чирей, язва' для праслав. *verd (в этом случае глагол - отыменное образование). Расхождения у этимологов наблюдаются только относительно генетических связей: одни связывают слав. *verdz с и.-е. *uer-dh- 'расти', ср. лтш. ap-virde 'нарыв', др.-инд. vardhati 'растет' [Фасмер 1: 295; БЕР 1: 184], другие — и их большинство - с и.-е. *uer- $d$ - и *uer-s- 'приподнятость, возвышенность на земле, на коже': др.-в.-нем. warze, нем. Warze, др.-исл. warta 'бородавка' (*uordā) и нем. Werre 'ячмень на глазу', лат. verruca 'бородавка', 'бугорок', 'возвышенность вообще' [Фасмер 1: 295; Черных 1: 170; Pokorny 1151].

Второй вариант исторического развития мотивационных отношений у Ю. Покорного: слав. *verds 'рана' как продолжение и.-е. *uer-d- 'разрывать, царапать' [Pokorny 1163]. Менее известно предположение И. П. Петлевой, которая на основе анализа семантического поля производных слав. *verdb посчитала первичным значение 'повреждать (ранить), вредить; повреждение, вред', ее дополнительным аргументом была ссылка на И.И. Срезневского, который соотнес др.-рус. връдъ с др.в.-нем. wartjan, ср.-в.-нем. warden 'портить', гот. wardjan, др.-сканд. a-wardjan, vredh- 'malus' [Петлева 96-97; Срезневский 1: 318]. Эта гипотеза не получила широкого распространения и обсуждения.

Предположение И.П. Петлевой о первичном значении слав. *verds близко к тому, что ранее было высказано в словаре Ю. Покорного. Только Ю. Покорный в своем этимологическом словаре индоевропейского языка включает производные слав. *verdz в два разных (омонимичных) этимологических гнезда с корнем *ver-d-: 1) ст.-слав. врђдъ 'Schaden; вред, ущерб, повреждение', рус. веред 'Geschwür, Eiterbeule; нарыв, язва, абсцесс' определено как производное и.-е. *ver-d-, *ver-s- 'erhöchte Stelle (im Gelände oder in der Haut; приподнятое место (на местности или на коже)', то есть это первый выше названный вариант; 2) ст.-слав. врђдъ, рус. веред 'Wunde, рана' - производное и.-е. *uer- $d$ - 'aufreissen, ritzen; разрывать, царапать' [Pokorny 1151, 1163]. Таким образом, двойственность выводов по мотивационно-генетической характеристике производных слав. *verds остается. 
Задачи нового обращения к мотивационно-генетической характеристике производных слав. *verdb, могущей показать путь формирования абстрактного понятия «вред», следующие: 1) сопоставить мотивационно-генетические характеристики лексем, наиболее близких по семантике рус. вред и веред; 2) сравнить семантические поля омонимичных этимологических гнезд *uer-d- (по Ю. Покорному), 3) проверить наличие генетических или иных связей слав. *verds с др.-в.-нем. wartjan, ср.-в.-нем. warden 'портить', гот. wardjan (по отсылке И.И. Срезневского и следом за ним И. П. Петлевой; см. выше).

Лексемы, семантически наиболее близкие к вред, вредить, но отличающиеся функционально, - это портить, порча и пакостить, пакость. Эти лексемы, как и вред, вредить, в силу, очевидно, исторической глубины возникновения не имеют однозначно определяемого мотивировочного признака и для них необходим историко-этимологический анализ.

Лексемы портить 'приводить в негодность', 'делать плохим', 'вредить', порча 'действие и состояние по глаголу портить(ся)', устар. 'заболевание, вызванное, по суеверным представлениям, колдовством, наговором', исторически соотносятся с др.-рус. пъртити 'тратить', запъртити, испъртити 'расточить; истратить', и предполагается, что им генетически близки слова пороть, портной, то есть эта лексика выражает семантику деструкции (нарушения исходного состояния). Определение мотивировочного признака затрудняет значительная разрушенность этого этимологического гнезда, ср. относимые к однокорневым образованиям укр. запор (о)ток 'заморыш (о детях)', чеш. zaprtek 'испорченное яйцо', слвц. zaprtok 'яйцо-болтун', польск. zapar(s)tek ‘тж’ [Черных 2: 59; Brückner 645]. Можно предположить развитие значения 'негодный' из 'имеющий нарушенное исходное состояние'. О первичности мотивировочного признака 'негодный; приводить в негодность' может свидетельствовать особенность сочетаемости глагола портить: портить кому-л. (о чел.), но ср. вредить кому-л., чему-л., то есть исходно портить, порча определяло, видимо, предметы по негодности для человека, способности принести вред (кому?) человеку.

История и происхождение слова пакость также неоднозначны. По одной гипотезе слово пакость (пакостить) соотносят со ст.-слав., др.-рус. паки (пакы, пакъ) 'обратно', 'назад', 'наоборот', ‘напротив', ‘опять, вновь', опако 'назад; задом наперед’ и под., что позволяет предположить семантическую модель 'делать наоборот' $\rightarrow$ 'вредить, пакостить', поэтому пакость *‘сделанное наоборот; вредное' (ср. болг. па́кост 'вред’, словен. pákost 'превратность', чеш. pakost' ‘пакость', др.-рус. пакостник 'тот, кто причиняет зло, вред; мучитель', 'тот, кто действует против кого-л., чего-л., противник’ и др.) [Фасмер 3: 142, 188-189; Черных1: 615-616; СРЯ XI-XVII 14: 128-129]. Эта версия происхождения слова пакость была поддержана и определена как «наиболее убедительная» в недавно вышедшем очередном выпуске этимологического словаря славянских языков [ЭССЯ 40: 229]. Можно добавить, что эта модель номинации актуализируется и внутренней формой прилагательного противный и отвратительный (еще в XVII в. противити значило только 'быть отвратительным, отвращать от себя, 
а отвратный 'повернутый в сторону', 'содержащий отступничество') [СРЯ ХІXVII 13: 211].

Согласно второй гипотезе, более предпочтительным считается предположение, что «лучше производить праслав. *pakostb от о.-с. *kostb, с приставкой pá- (ср. názубa, nамять) и старшим значением можно считать что-нибудь вроде 'костный нарост’, откуда позже 'болезнь' (подагрическая?), отсюда далее — 'вред, несчастье, зло’», ср. в.-луж. pakósć ‘костный нарост', чеш. pakostnice 'подагра', польск. pakość 'злоба', хотя в.-луж. pakósćić 'воровать, тащить' (собственно 'наносить ущерб, вредить' [Черных 1: 616].

P.М. Цейтлин специально занималась вопросом о значениях приименной приставки $n a ́-$ в славянских языках и пришла к выводу, что па- как словообразовательный элемент восходит к глубокой древности, вероятно, к балто-славянской эпохе, входит в основной славянский словообразовательный фонд, в современных славянских языках непродуктивна, семантика ее стерта, размыта временем. Слово пакость она включает в ту группу производных с приставкой $n a-$, в которой семантика приставки определяется как отрицание значения, выраженного корнем того же слова, и словам этой группы в целом присущ оттенок осуждения, неодобрения, презрения, иногда такие слова относятся к бранным. Развитие абстрактного значения у слова пакость предполагается из конкретного ‘болезненный, ненормальный нарост на кости' [Цейтлин 205-224].

Приставку $n a-$ с тем же значением Р.М. Цейтлин выделяет и в слове паскуда, в слове по семантике неодобрения, презрения близком слову пакость, ср. паскудить 'делать негодным, скверным; портить' (Нет уж, Петр Степаныч, пожалуйcma, не паскудь ухи [руками]. Мельников-Печерский). В таком значении глагол дается в контекстах из произведений XIX в., в современном русском употребительно значение 'гадить, пачкать', подобно груб., прост. паскудничать 'делать мерзости, гадости' [СРЯ 3: 28]. Однокорневые образования известны в некоторых славянских языках: укр. па́скуд, паскýда, по́скудзь 'пакостник, подлец', блр. паски́дства, польск. paskudztwo 'пакость', чеш. paskuda ‘škoda, пакость' [Фасмер 3: 212; Черных 1: 615; Machek 355]. Привлечение исторических данных (др.-рус. паскудьнь 'бедный, скудный', поскудовати 'испытывать недостаток' (XII в.), поскуду 'в небольшом количестве, мало, скудно’ (XV в.) [Фасмер 3: 212; СРЯ XI-XVII 17: 171]) показывает, что приставка $n a-$, как в случае с пакость, привносит отрицательную оценку в семантику корневой морфемы скуд-, то есть отрицательно, презрительно оценивается малое количество, создающее неполноценность, негодность субъекта/ объекта.

Таким образом, мотивационно-генетические характеристики близких по значению к вред лексем оказываются также не однозначно определяемыми в этимологических источниках. Остальные лексемы этого лексико-семантического поля имеют прозрачные мотивационные отношения (ущеерб, урон, убыток, изъян, наклад, салаз и др.).

Еще одна возможность прояснить мотивационно-генетическую характеристику рассматриваемого словообразовательно-этимологического гнезда - сравнить 
семантические поля омонимичных этимологических гнезд *uer-d-, в состав которых Ю. Покорный отнес слав. *verdъ.

Одно этимологическое гнездо и.-е. *uer- реконструируется в словаре Ю. Покорного с общим значением 'разрывать, царапать'. Его производная основа *uerdпредставлена в индоевропейских языках рядом вариантов, ср. *verdz: ст.-слав. vrěds, pус. véred 'Wunde, рана', авест. varadva- 'мягкий, рыхлый'; *ured-: др.-инд. vrandin- 'становиться рыхлым'; *vrēd-: др.-прус. redo 'борозда на пашне'; *urōd-: лат. rodo 'грызть, разъедать', англосакс. wrōtan 'копать, рыть', *urod-: швед. диал. rota, ruta 'копать, рыть'. Близкие значения и у производных основы с другим расширением — *uornā: алб. varrë 'рана', польск. wrona, чеш. vrana 'отверстие', рус. диал. ворона́ 'на судне - отверстие, где проходит руль', воро́нка 'приспособление в виде конуса для переливания и фильтрования жидкости; коническая яма в земле от разрыва артснаряда'; *uro-no: др.-инд. vraná- 'рана; трещина', *vrō-nā: слав. rana 'Wunde, рана' [Pokorny 1163].

Во втором случае производные слав. *verd - ст.-слав. vrědz 'Schaden; вред, ущерб, повреждение', рус. веред 'Geschwür, Eiterbeule; нарыв, язва, гнойник' соотнесены с производными и.-е. *uer- $d$ - и *uer-s- 'приподнятость, возвышенность на земле, на коже’ (<*uer-): перс. balū ‘бородавка' (иран. *vard-), др.-в.-нем. warza, нем. Warze 'бородавка; сосок (на груди)', англосакс. wearte, др.-исл. warta 'бородавка' (герм. *uordā) и нем. Werre 'ячмень на глазу', лат. verruca 'бородавка', 'бугорок', 'возвышенность вообще', англосакс. wearr 'мозоль, бородавка'; того же корня без расширения лат. varus, $i$ 'прыщ (на лице)', varulus 'ячмень на глазу', норв. диал. vere 'опухоль под кожей (о корове)'. Остальная часть этого этимологического гнезда с основой *uer-s- в прямом значении связана с обозначением высоты, ср. др.-инд. varșmán- 'Höhe, Oberstes', литов. viršùs 'das Obere, höchste Spitze', слав. *vbrchъ, pус. верх, вершина [Pokorny 1151-1152].

Сопоставление семантических полей производных вышеприведенных этимологических гнезд с семантикой производных слав. *verdъ позволяет отнести славянские производные к первому этимологическому гнезду, поскольку нарыв, чирей, язва - это прежде всего поражение кожи, рана (с выделением гноя), но не просто опухоль, бугорок, бородавка. Предполагаемое направление генетических связей подсказывает и семантическая структура ст.-слав. врђдъ в сопоставлении с семантикой греческих эквивалентов: ст.-слав. врђдъ 1. 'рана, ранение’ (ла́ $\theta$ о ‘страсть, страдание', $\lambda \omega ́ \beta \eta$ 'обида; бесчестие, истязание, гибель') // греч. нет 'на-

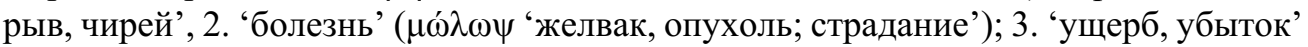

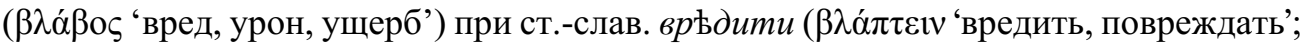

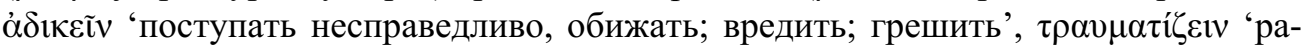

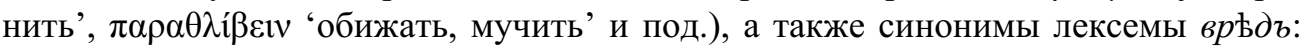
рана, строупь, творъ; проказа, прокажение; бользнь, недпгъ, наsа; врђждение, пакость [CC 124-125].

Семантика производных этимологического гнезда, к которому, как полагаем, можно отнести слав. *verdb, наличие греческих эквивалентов в источниках пе-

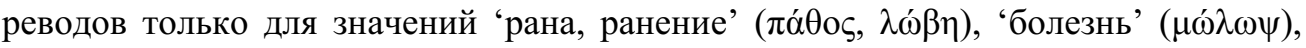


‘ущерб, убыток’ ( $\beta \lambda \alpha ́ \beta о \varsigma)$ и их отсутствие для значения 'нарыв, чирей’ свидетельствуют, что это значение ('нарыв, чирей') является собственно славянской новацией. Таким образом, сопоставление мотивационно-генетических характеристик лексем, наиболее близких по семантике рус. вред и веред (порча, пакость), результат сравнения семантических полей омонимичных этимологических гнезд *uer- $d$ (по Ю. Покорному) и отсутствие значений типа 'нарыв, чирей' у греческих эквивалентов ст.-слав. врђдъ дает основание, как полагаем, допустить, что первичным для слав. *verdb было обозначение нарыва/раны, повреждения воспалительного характера, проявляющегося на коже и связанного с какой-либо болезнью (откуда и значение 'болезнь' у производных*verdb!), в отличие, вероятно, от слав. *rana (предполагаемого однокорневого образования), связанного с обозначением раны, повреждения, нанесенного острым предметом, оружием (слав. *rana как предполагаемое однокорневое образование от и.-е. *urōna < и.-е. *uer- 'разрывать', 'царапать', ср. др.-инд. vraná- 'рана; трещина', алб. varrë 'рана', с изменением начального ur->r) [Pokorny 1163; Черных 1: 98-99]).

Косвенным аргументом в пользу высказанного предположения об исходном значении слав. *verdъ (или для отказа от него) может быть результат проверки наличия и характера связи между связи слав. *verd $\mathbf{b}$ и древнегерманской лексической группой (др.-в.-нем. wartjan, ср.-в.-нем. warden 'портить', гот. wardjan). На возможность близости этой славянской и древнегерманской лексики указал в своем словаре И.И. Срезневский со ссылкой на «Грамматику» Я. Гримма [Срезневский 1: 318], это предположение приведено в словаре Ф. Миклошича, его поддержала И. П. Петлева, на основе анализа производных слав. *verdz предположившая первичность значения 'повреждать (ранить), вредить; повреждение, вред' [Петлева 96-97]; как возможное его оценивает А. Е. Аникин [Аникин 6: 275]. Приведенные в качестве соответствий древнегерманские лексемы в современных германских языках прямого (с тем же значением) продолжения не имеют, и их генетические связи к рассмотрению в исследованиях относительно слав. *verds не привлекались.

Обращение по ссылке И.И. Срезневского к «Грамматике» Я. Гримма не дало результата, но в словаре братьев Гримм при рассмотрении спорного по происхождению прилагательного wert (cp. англ. worth) 'стоящий, ценный', сближаемого с герм. *werpa (-wärts и т.д., лат. арх. vorsus, лат. versus 'в сторону, по направлению к’ и т.д.), высказывается предположение, что из германских языков заимствованы кимр. gwerth, фин. verta, лит. vertas, др.-прус. werts и ст.-слав. -vrědŭ (in: nevrědŭ 'unwürdig') [Grimm 444-445]. То есть речь идет об омонимичном ст.слав. неврђдоу, неврђдъ сътворити 'счесть неподходящим, отвергнуть' (ему соответствуют др.-рус. врђдьныи 'достойный', болг. вреден, серб. вре́дан 'достойный, стоящий; трудолюбивый', вреюдно 'полезно, стоит') как о южнославянском (балканском) заимствовании из древневерхненемецкого [Skok 3: 625]. Лексемы, омонимичные в славянских языках, на уровне германских языков оказываются генетически близкими: не только в Словаре братьев Гримм, но и у Ю. Покорного, и в современном этимологическом словаре немецкого языка (под ред. В. Пфайфера) нем. wert (англ. worth) 'стоящий, ценный' по происхождению соотносится 
с нем. werden (< герм. *werpa <и.-е. *uert- 'вертеть'; исходное значение нем. wert (англ. worth) 'als Äquivalent gegenüberstehend', 'als Gegenwert dienender Preis'), подобно лат. pretium 'цена, стоимость, Wert, Preis' при его родстве с др.-инд. prati 'против, относительно', слав. *protivъ: *pretivъ и под. [Pokorny 1157; EWD 3: 1965]. Хотя у автора этимологического словаря прагерманского языка (Kroonen 2013) есть сомнения на этот счет (An adjective of unknown origin) [Kroonen 581].

Что же касается связи со славянской лексикой, обозначающей «вред», похоже, что только в словаре древневерхненемецкого языка О. Шаде (1872-1882) в ряд с др.-в.-нем. wartjan, wartan, werten 'портить, вредить', 'exulcerare, покрывать нарывами, вызывать нагноение', др.-сакс. wardjan 'портить', англосакс. verdan 'поранить, повредить' ставится слав. vrědz, vrěditi [Schade 1101]. Но названную древнегерманскую лексику все известные этимологические словари безусловно относят к производным и.-е. *uert- (cp. pус. вертеть) и указывают на несохранность ее в современных германских языках [EWD 3: 1965; Kroonen 574, 581-582; Kluge 853; Fraenkel 1204-1205].

В германских языках широко представлены однокорневые образования с другой огласовкой корня, уже далекие по значению: гот. waipan, др.-сев. verđa, др.-англ. weordan, др.-в.-нем. werdan, нем. werden и т. п. 'становиться, делаться, превращатьcя; to come about, happen, become’. Эта группа лексики, производная от прагерм. *werpan-, закономерное продолжение и.-е. *uért-e- (по I общегерманскому передвижению $t>p$, в немецком $p>d$ ), ср. скр. vártate 'to turn (around), roll', лат. verto, -ere 'to turn', слав. *vbrtěti ‘вертеть' (<и.-е.*ur-t), литов. virsti (virstù) 'валиться, превращаться; to fall, collapse, turn into', др.-прус. wīrst 'to become' (<*urt-ske-). От нулевой ступени корня образовано и герм. *wurdi- f. 'судьба, fate, chance': др.-англ. wyrd f., др.-сакс. wurd f., др.-в.-нем. wurt f. [Kroonen 581-582; 600; Kluge 583; Черных 1: 144], ср. рус. превратности судьбы. Такое изменение значения от 'вертеть' к 'превращаться, становиться' достаточно известно, ср. англ. become, фp. devenir и др. [Buck 636].

Интересующие нас вышеприведенные древнегерманские глаголы со значением 'портить, вредить; ранить' (др.-в.-нем. wartan, werten, др.-сакс. wardjan, англосакс. werdan) являются продолжением герм. *wardjan 'портить; to cause to degenerate', сюда относятся и гот. fra-wardjan 'to corrupt, destroy', др.-англ. $\bar{a}$-wierdan 'to damage', др.-в.-нем. far-werten 'to damage, corrupt', др.-сакс. far-werthan 'to perish, ruin'. В прагерманской форме, восходящей к и.-е.*uort-éie- (с ударением на основе), произошло озвончение глухого щелевого (по закону Вернера), в немецком $p>d$. В современных германских языках эта лексика не получила продолжения. От той же ступени корня есть аналогичные по форме образования и в других индоевропейских языках — литов. vartýti, лтш. vàrtît 'to turn, turn over', др.-прус. wartint 'to turn', ст.-слав. vratiti sę 'to return, bring back' [Kroonen 574]. В словарях А. Вальде, Й. Хофмана и Ю. Покорного предложено следующее объяснение изменения значения от 'вертеть, превращать' к 'превращать(ся), изменять(ся) в худшую сторонy': ‘eine Wendung zum Übel nehmen', ‘eine Wendung zum Schlimmen nehmen lassen' [Pokorny 1157; W.-H. 2: 764-765]. Это переосмысление показывает формирование 
представления о действии «портить» как нарушении, искажении, превращении исходного, «правильного», состояния вещей в «неправильное», вредное для субъекта (и наряду с этим понимание «превращения» как «становления (иной сущности)») и может быть типологически сопоставлено с предполагаемой моделью образования слова пакость как * ‘сделанное наоборот’ (об этом выше).

Подобное направление развития семантики производных от корня *верт- есть в русском языке, как и других славянских языках, ср. pус. вертеть/nереворачивать/ превращать с их производными перевертыи, отвернуть(ся)/отвращение, извращение, обернуть (ся)/оборотень и др. Но значение 'вред, порча; приносить вред, портить' закрепилось за производными слав. *verds, которое генетически не связано с производными от *vert-, подобно тому, что наблюдается в германских языках. И если изменение семантики у производных прагерм. *werp-/*ward- от 'вертеть' к 'превращаться, становиться' отмечено в самых ранних письменных памятниках и во всех германских языках и типологически достаточно известно, то развитие исходной семантики от 'вертеть' до 'портить, вредить; ранить' ареально и хронологически ограничено: такое изменение семантики представлено только в древнезападногерманских языках (др.-англ., др.-сакс., др.-в.-нем.) и готском. Позже эта лексика была утрачена, ее следов в современных германских языках нет. Учитывая, что восточногерманские языки (к которым относится готский) не одно столетие существовал на территории, смежной с землями западногерманских племен и праславян в междуречье Вислы и Одера, затем в Прикарпатье и на Дунае, куда продвинулись восточногерманские племена и расселялись славяне [Трубачёв 25-26; Седов 142150], можно предположить контактный характер формирования интересующей нас лексики германских языков, формально и семантически близкой производным слав. *verdz. Но неясен характер и время этого контактного взаимодействия, возможно, субстратного характера, учитывая расселение в междуречье Вислы и Одера германских и славянских племен в первые века н.э. [Седов 142-147].

Существенно осложняет вопрос тот факт, что предполагаемая соотнесенность славянской и древнегерманской лексики касается только ее глагольной части, ничего подобного именным производным слав. *verdъ нет: др.-в.-нем. scado, нем. Schade(n) 'вред, ущерб' и их однокорневые образования в других германских языках, продолжающие прагерм. *skapjan 'to harm, do wrong, причинять зло, вредить', *skōpi- 'harmful, вредный, пагубный', по происхождению относятся, вероятно, к глубокому индоевропейскому слою (учитывая их предполагаемые генетические связи в армянском, древнегреческом, кельтских языках) [EWD 2: 1174-1175; Kroonen 441]; англ. harm 'вред, зло; обида', '(по)вредить', harmful 'вредный, пагубный’, harmless 'безобидный, безвредный’ родственны выражению отрицательной этической оценки в лексике славянских и иранских языков, - 'стыд, срам, позор', ср. слав. * sormъ > рус. срам и его аналоги в других славянских языках; авест. f̌́arzma 'стыд', ст.-перс., перс. шӓрм 'срам, стыд, позор' и др. [EWD 1: 509-510; Черных 2: 196].

Все сказанное позволяет предположить, что вполне вероятная связь слав. *verdz с лексикой определенного (западного и восточного, за исключением 
скандинавского) древнегерманского ареала имеет характер не генетической связи, а историко-ареальной, являясь результатом праславянско-германских контактных (субстратных?) отношений. Соответственно, это не противоречит высказанному выше предположению, что первичным для слав. *verdb было обозначение нарыва/ раны, повреждения воспалительного характера, проявляющегося на коже и связанного с какой-либо болезнью (в отличие от слав. *rana).

\section{Литература}

Аникин A. E. Русский этимологический словарь. Вып. 6. М.: Рукописные памятники Древней Руси: издатель А. Кошелев, 2012.

БЕР - Български етимологичен речник: в 3 т / Съст. Вл. Георгиев, Ив. Глъбъв и др. София: БАН, 1971-1986.

Дронова Л.П. Что такое вред? (мотивационно-генетические связи рус. вред) / в соавт. с Я. Лю // Вестник Томского госуниверситета. 2016. №412. С. 14-19.

Петлева И. П. Этимологические заметки по славянской лексике. І. // Этимология 1972. М.: Наука, 1974. С. 81-99.

Седов В. В. Славяне: Историко-археологическое исследование / Ин-т археологии Рос. Академии наук. М.: Языки славянской культуры, 2002. 624 с.

Срезневский И. И. Материалы для словаря древнерусского языка по письменным памятникам: в 3 т. СПб., 1893-1912.

СРЯ - Словарь русского языка: В 4 т. / ред. А. П. Евгеньева. 2-е изд. М.: Рус. яз., 1999.

СРЯ XI-XVII - Словарь русского языка XI-XVII вв. / Глав. ред. С. Г. Бархударов и др. М.: Наука, 1975-.

СC - Старославянский словарь (по рукописям X-XI веков) / Под ред. Р.М. Цейтлин, Р. Вечерки и Э. Благовой. 2-е изд., стереотип. - М.: Русский язык, 1999.

Трубачёв О. Н. Этногенез и культура древнейших славян: Лингвистические исследования / Отв. ред. Н. И. Толстой. Изд-е 2, доп. М.: Наука, 2002. 489 с.

Фасмер М. Этимологический словарь русского языка: в 4 т. / пер. с нем. и доп. О.Н. Трубачёва. М., 1964-1973.

Цейтлин Р. М. К вопросу о значениях приименной приставки $n a ́-$ в славянских языках // Ученые записки Института славяноведения. Т. IX, 1954 г. М.: Изд-во АН CCCP, 1954. C. 205-224.

Черных П.Я. Историко-этимологический словарь современного русского языка: В 2 т. М.: Русский язык, 1994.

ЭССЯ - Этимологический словарь славянских языков. Праславянский лексический фонд. Вып. 40: * gborъkъ — *pakъla. М.: Наука, 2016.

Brückner A. Słownik etymologiczny języka polskiego. Warszawa: Wiedza Polszechna, 1985 (przedruk z Kraków 1927).

Buck C.D. A dictionary of selected synonyms in the principal Indo-European languages. Chicago, 1949. 
EWD - Etymologisches Wörterbuch des Deutschen / durchges. und erg. von W. Pfeifer. Bd. 1-3. Berlin, 1989.

Fraenkel E. Litauisches etymologisches Wörterbuch. Bd. 1-2. Heidelberg; Göttingen, 1955.

Grimm - Deutsches Wörterbuch von Jacob und Wilhelm Grimm. Bd. 1-16. Berlin; Leipzig, 1854-1960. T. 14 (1/2).

Kluge F. Etymologisches Wörterbuch der deutschen Sprache. 21. Aufl. Berlin ; New York, 1975.

Kroonen G. Etymological Dictionary of Proto-Germanic / Leiden Indo-European Etymological Dictionary Series. Edited by A. Lubotsky. Vol. II. Leiden, Boston: Brill, 2013.

Machek $V$. Etymologický slovník jazyka českého a slovenského. Praha, 1957.

Pokorny - Pokorny J. Indogermanisches etymologisches Wörterbuch. — Bern, 1959.

Schade O. Altdeutches Wörterbuch. Bd. 1-2. Halle, 1872-1882 (1969).

Skok P. Etimologijski rječnik hrvatskoga ili srpskoga jezika. Kn. 1-3. Zagreb, 1971-1973.

W.-H. - Walde A., Hoffmann J. B. Lateinisches etymologisches Wörterbuch. Bd. 1-2. Heidelberg, 1939-1954.

\author{
L.P. Dronova \\ Tomsk State University \\ (Russia, Tomsk) \\ lpdronova@mail.ru
}

\title{
FURTHER EXPLORATION OF THE FORMATION OF THE CONCEPT "HARM" IN THE SLAVIC LANGUAGES
}

The article continues to explore the problem of the motivational component of the nuclear lexeme in the lexical and semantic field of 'harm' in the Slavic languages.

The comparison of motivational and genetic characteristics of the lexemes whose semantics closely resembles that of the Rus. vred, the comparison of the semantic fields of homonymous etymological nests *uer-d-, into which Yu. Pokorniy includes the Slav. *verdb and its various meanings ('abscess', 'disease' and 'lesion'), the absence of meanings similar to 'abscess, boil' in the Greek equivalents of the Old Slav. $в р ђ \partial z$, as well as the checking of facts on a number of Old Germanic languages regarding the presence/absence of genetic relatedness to the reflexes of the Slav. *verdb, give a strong reason to suppose that the primary meaning for the Slav. *verdb was an abscess-like wound, an inflammatory injury which manifested itself on the skin and was related to a disease (which is also the source of the "disease' meaning of *verd $b$ derivatives). It seems plausible that this nomination was formed in order to distinguish it from a wound caused by a sharp object or a weapon, usually expressed with the Slav. *rana, supposedly formed from the same Indo-European root *urōna.

Key words: Slavic languages, etymological nest of Slav. *verdъ, Slavic-German links. 


\section{References}

Anikin A.E. (2007-2012) Russkiy etimologicheskiy slovar' [Russian Etymological Dictionary]. Vol. 1-6. Moscow: Znak Publ.

Brückner A. (1985) Stownik etymologiczny języka polskiego [Etymological Dictionary of the Polish Language]. Warszawa: Wiedza Polszechna Publ.

Buck C. D. (1949) A dictionary of selected synonyms in the principal Indo-European languages. Chicago.

Chernykh P.Ya. (1994) Istoriko-etimologicheskiy slovar' sovremennogo russkogo yazyka: $\mathrm{v} 2 \mathrm{t}$. [Historical and etymological dictionary of modern Russian language: in 2 vols]. Moscow: Russkiy yazyk.

Deutsches Wörterbuch von Jacob und Wilhelm Grimm. (1854-1960). Bd. 1-16. Berlin: Leipzig. Bd. 14 (1/2).

Dronova L.P., Liu Y. (2016) What Is Harm? (Motivational and Genetic Links of Rus. vred 'harm'). Tomsk State University Journal. 412. pp. 14-19 (In Russian). DOI: 10.17223/15617793/412/2.

Etimologicheskiy slovar' slavyanskikh yazykov. Praslavyanskiy leksicheskiy fond (2016) [Etymological Dictionary of the Slavic Languages. Proto-Slavic Lexical Stock]. No. 40: *gborъkъ — * pakъla. Moscow: Nauka Publ.

Etymologisches Wörterbuch des Deutschen (1989). Ed. W. Pfeifer. Bd. 1-3. Berlin.

Fasmer M. (1967-1973) Etimologicheskiy slovar' russkogo yazyka: $\mathrm{v} 4$ t. [Etymological Dictionary of the Russian language: in 4 vols]. Translated from German by O. N. Trubachev. Moscow: Progress.

Fraenkel E. (1955) Litauisches etymologisches Wörterbuch [Lithuanian Etymological Dictionary]. Bd. 1-2. Heidelberg, Göttingen.

Georgiev Vl., Glebov Iv. (1971-1986) Blgarski etimologichen rechnik [Bulgarian Etymological Dictionary]. Vol. 1-3. Sofia: Bulgarian Academy of Science.

Kluge F. (1975) Etymologisches Wörterbuch der deutschen Sprache [Etymological Dictionary of German]. 21. Aufl. Berlin, New York.

Bd. 1-3.

Kroonen G. (2013) Etymological Dictionary of Proto-Germanic / Leiden IndoEuropean Etymological Dictionary Series. Ed. A.Lubotsky. Vol. 2. Leiden, Boston: Brill.

Machek V. (1957) Etymologický slovník jazyka českého a slovenského. Praha.

Petleva I.P. (1974) Etimologicheskie zametki po slavyanskoy leksike. I [Etymological Notes on Slavic vocabulary. I]. In: Trubachev, O. N. (ed.) Etimologiya 1972 [Etymology 1972]. Moscow: Nauka Publ.

Pokorny J. (1959) Indogermanisches etymologisches Wörterbuch. Berne: A. Francke.

Schade O. (1872-1882/1969) Altdeutches Wörterbuch. Bd. 1-2. Halle.

Sedov V.V. (2002) Slavyane: Istoriko-arkheologicheskoe issledovanie [The Slavs: A Historical and Archeological Study]. Moscow: Yazyki slavyanskoy kul'tury Publ.

Skok P. (1971-1973) Etimologijski rječnik hrvatskoga ili srpskoga jezika. Kn. 1-3. Zagreb. 
Slovar' russkogo yazyka: V 4 t. (1999) [Dictionary of the Russian Language: in 4 vols]. Ed. A.P. Evgen'eva. 2nd ed. Moscow: Russkiy yazik Publ.

Slovar' russkogo yazyka XI-XVII vv. (1975-) [Dictionary of the Russian Language of the $11^{\text {th }}-17^{\text {th }}$ Centuries]. Ed. D. N. Shmelev. Moscow: Nauka Publ.

Sreznevskiy I. I. (1903) Materialy dlya slovarya drevnerusskogo yazyka: v 3 t. [Materials for the dictionary of Old Russian language: in 3 vols]. St. Petersburg: Tipografiya Imperatorskoy Akademii Nauk.

Trubachev O.N. (2002) Etnogenez i kul'tura drevneyshikh slavyan: Lingvisticheskie issledovaniya [Ethnogenesis and Culture of the Ancient Slavs: Linguistic Studies]. Ed. N. I. Tolstoy. 2nd ed. Moscow: Nauka Publ.

Tseytlin R. M. (1954) K voprosu o znacheniyakh priimennoy pristavki pá- $v$ slavyanskikh yazykakh [On the meaning of the nominal prefix $p a$ - in the Slavic languages]. In: Uchenye zapiski instituta slavyanovedeniya [Scientific Notes of the Institute of Slavic Studies]. Vol. 9. Moscow: Academy of Sciences of the Soviet Union. pp. 205-224.

Tseytlin R. M. Vecherka, R. \& Blagova, E. (eds) (1999) Staroslavyanskiy slovar' (po rukopisyam X-XI vekov) [Old Slavonic Dictionary (based on manuscripts of the 10th11th centuries)]. 2nd ed. Moscow: Russkiy yazyk Publ.

Walde A., Hofmann I.B. (1939-1954) Lateinisches etymologisches Wörterbuch [Latin Etymological dictionary]. Bd. 1-2. Heidelberg. 